\title{
Spatial searches for journal articles
}

\author{
Sanet Carow ${ }^{\mathrm{a},{ }^{*}}$, Curtis Mashimbye ${ }^{\mathrm{b}}$, Peter Schmitz $^{\mathrm{c}}$ \& Ruan Schoeman ${ }^{\mathrm{c}}$ \\ ${ }^{a}$ University of South Africa, sanetpc@ unisa.ac.za \\ ${ }^{b}$ Esri South Africa, cmashimbye@esri-southafrica.com \\ ${ }^{c}$ University of South Africa, schimpmu@unisa.ac.za \\ ${ }^{d}$ University of South Africa, eschoerc@unisa.ac.za \\ * Corresponding author
}

Keywords: spatial searches, peer-reviewed articles, web map, SAJG

\begin{abstract}
:
As GIS and Cartographic specialists, we are well aware of the powerful analysis capabilities of a GIS. There is no need to expand on the functionalities of a GIS and how a GIS assist in managing daily tasks. As researchers in GIS and Cartography, we often search for more information on specific research topics. A list of potential articles covering the issues we are interested in is returned in all instances. But when it comes to research in GIS and Cartography, we often work within a research or study area. We raise the question: Why do we accept a list of research articles if most of these articles have a physical location on Earth or if your research occurs within a specific research area?
\end{abstract}

In GIS terms, a spatial search - also called a geospatial search - is a process of identifying and investigating spatially distributed phenomena that serve as the basis for a locational decision. (Sciencedirect, 2021). A spatial search takes data with a geographic location and enhances the search results by limiting them to comply with a set of criteria (Lindsley, 2016). This project investigates the viability to apply spatial searches to identify journal articles relevant to a specific topic and area.

We focused on research articles published in the South African Journal of Geomatics (SAJG, 2021). The SAJG has a long history of publications and dates back to 1923, when the first article was published in a journal called the South Africa Survey Journal. After two name changes, the SAJG published its first volume in 2012 (SAJG, 2021). Currently, the SAJG receive submissions from primarily African countries, including Nigeria, Egypt, Ghana, and South Africa. New issues are published twice a year with about 6 to 8 peer-reviewed articles per volume. Since 2012, the SAJG published 232 articles.

We searched through all the published articles to identify the study area of each article. The study area was then used to locate the journal article on a world map. The title of the article, author(s), keywords, abstract, volume number and year of publication was captured as attribute data. In some instances, a research article may not have a physical location. Examples of research articles without a physical location include topics such as GIS and survey standards, GIS curricula, registering of GISc professionals and surveying education in mining engineering, to name a few. These articles were omitted from this study.

The spatial locations and related attribute data were captured using GIS software and published on a web map. The web map will be inserted on the website of the SAJG. The web map allows a user to search for articles published in an identified area. The search can be refined by searching according to the author of the article or the date of publication. The resultant articles can be identified on the map. The abstract is available to assess if the article is related to the user's research. The published article can then be found through a link that is captured as part of the attribute data.

Figure 1 indicates articles published of which the study area is located in the Western Cape Province in South Africa. 


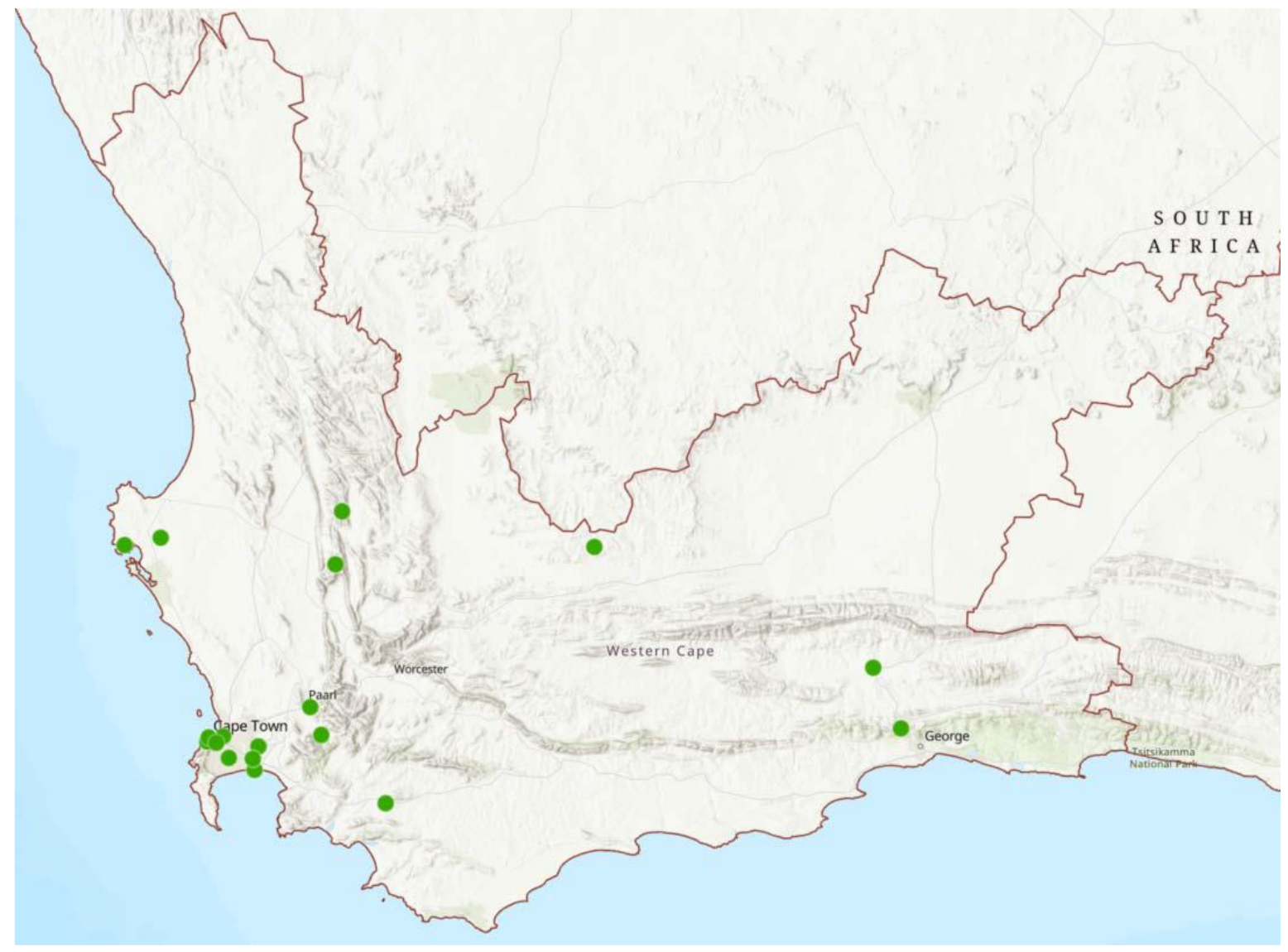

Figure 1. Articles published with study area located in the Western Cape Province in South Africa.

An initial search on the internet indicates that there is currently no journal presenting articles according to the physical location of the study area on a map. The closest we could get to the idea of presenting information on a map was on the website of the International Review of Research in Open and Distributed Learning that has a map of the number of page views and the location of readers according to their IP addresses (IRRODL,2021).

Peer-reviewed articles available on a map make a unique contribution towards identifying articles relevant to a research project or potential research project that may be overlooked if a list of articles is returned to the user. A person who wants to obtain more information about a specific area or want to do research in a specific area can easily identify other research projects conducted in the area. If a researcher has a potential research topic, it will be easy to determine other research projects undertaken in the area and assess how these relate or differ from the proposed research project.

At the time of writing this abstract, we geolocated all articles from 2012 - 2014 and 2019-2021. Once all the articles are captured, the viability of doing spatial searches for journal articles will be tested by sending a questionnaire to leading researchers from Universities and the Geomatics industry in South Africa. The feedback received will be used to improve the information captured and how it is presented on the map. 